\title{
Pemodelan Struktur Bawah Permukaan Zona Subduksi dan Busur Gunungapi Jawa Timur berdasarkan Analisis Data Gravitasi
}

\author{
Muhamad Ragil Setiawan* dan Ari Setiawan
}

\begin{abstract}
Abstrak
Zona subduksi di selatan Jawa Timur merupakan bagian dari subduksi panjang yang terbentuk akibat tumbukan lempeng Indo-Australia dan Eurasia. Keberadaan subduksi tersebut menjadi menarik untuk dikaji karena turut mempengaruhi aktivitas gunungapi dan potensi bencana alam di daerah tersebut. Pengkajian zona subduksi dan gunungapi dilakukan dengan melakukan pemodelan struktur bawah permukaan menggunakan anomali gravitasi dengan bantuan program Grablox dan Bloxer. Pemodelan dilakukan terhadap data sekunder anomali regional, dan anomali lokal. Data anomali gravitasi diperoleh dari Bureau Gravimetrique Internationale (BGI). Pembuatan model dilakukan dengan teknik inversi menggunakan metode Singular Value Decomposition (SVD) dan optimasi Occam. Hasil penelitian menunjukkan adanya penipisan kerak samudera rata-rata dari $20 \mathrm{~km}$ menjadi $15 \mathrm{~km}$ ke arah utara. Penipisan tersebut disebabkan adanya lapisan mantel atas yang menonjol dan mendesak kerak yang disebut flexural bulge. Ketebalan batuan sedimen pada cekungan busur belakang sebesar $\sim 4,50 \mathrm{~km}$, dan semakin ke timur nilainya semakin berkurang. Keberadaan dapur magma pada busur gunungapi di Jawa Timur pada umumnya diperkirakan pada kedalaman $\sim 6 \mathrm{~km}$.
\end{abstract}

kata kunci: anomali gravitasi; zona subduksi dan gunung api, Grablox;Bloxer; pemodelan anomali gravitasi

\section{Abstract}

The subduction zone to the south of East Java is a part of a long subduction formed by collision of Indo-Australian and Eurasian plate. The existence of the subduction is important to be studied since it also affects the volcanic activity and geo-hazards in the area. The study of subduction zone and volcano was conducted by modeling the subsurface structure using gravity anomaly with the help of program Grablox and Bloxer. The modeling was conducted on secondary data of regional anomaly, and local anomaly. The data of secondary gravity anomaly was obtained from Bureau Gravimetrique Internationale (BGI). The modeling construction was performed by inversion technique applying Singular Value Decomposition (SVD) method and Occam optimization. Result of the study indicates there is oceanic crust thinning in average from $20 \mathrm{~km}$ to $15 \mathrm{~km}$ to the north. The thinning is caused by the protuding upper mantle pressuring crush called flexural bulge. The thickness of sedimentary rocks in the back-arc basin is $\sim 4.50 \mathrm{~km}$. The deeper it is to the east, the more the value will decrease. The existence of magma chamber generally is estimated at depth of $\sim 6 \mathrm{~km}$.

keywords: $\mathrm{NiFe}_{2} \mathrm{O}_{4}$; crystal structure,; magnetic susceptibility

\section{Pendahuluan}

Wilayah Jawa Timur merupakan salah satu daerah di Indonesia yang memiliki banyak gunungapi aktif sampai saat ini. Deretan gunungapi aktif membentang

\footnotetext{
*Korespondensi: ragil.setiawan@mail.ugm.ac.id

Jurusan Pendidikan Fisika, Fakultas Teknik Matematika dan IImu Pengetahuan Alam, Sekip Utara PO BOX BLS 21, 55281 Yogyakarta, Indonesia

Informasi lengkap tentang penulis dapat dilihat pada akhir artikel
}

dari barat ke timur yang merupakan bagian dari cincin api dunia [1]. Keberadaan busur gunungapi aktif tersebut tidak terlepas dari keberadaan sistem subduksi (Gambar 1) yang terbentuk dari tumbukan lempeng Indo-Australia dan Eurasia. Keberadaan subduksi tersebut selain menyebabkan munculnya busur gunungapi juga memicu aktivitas tektonik yang berada di daerah Jawa Timur. Salah satu 


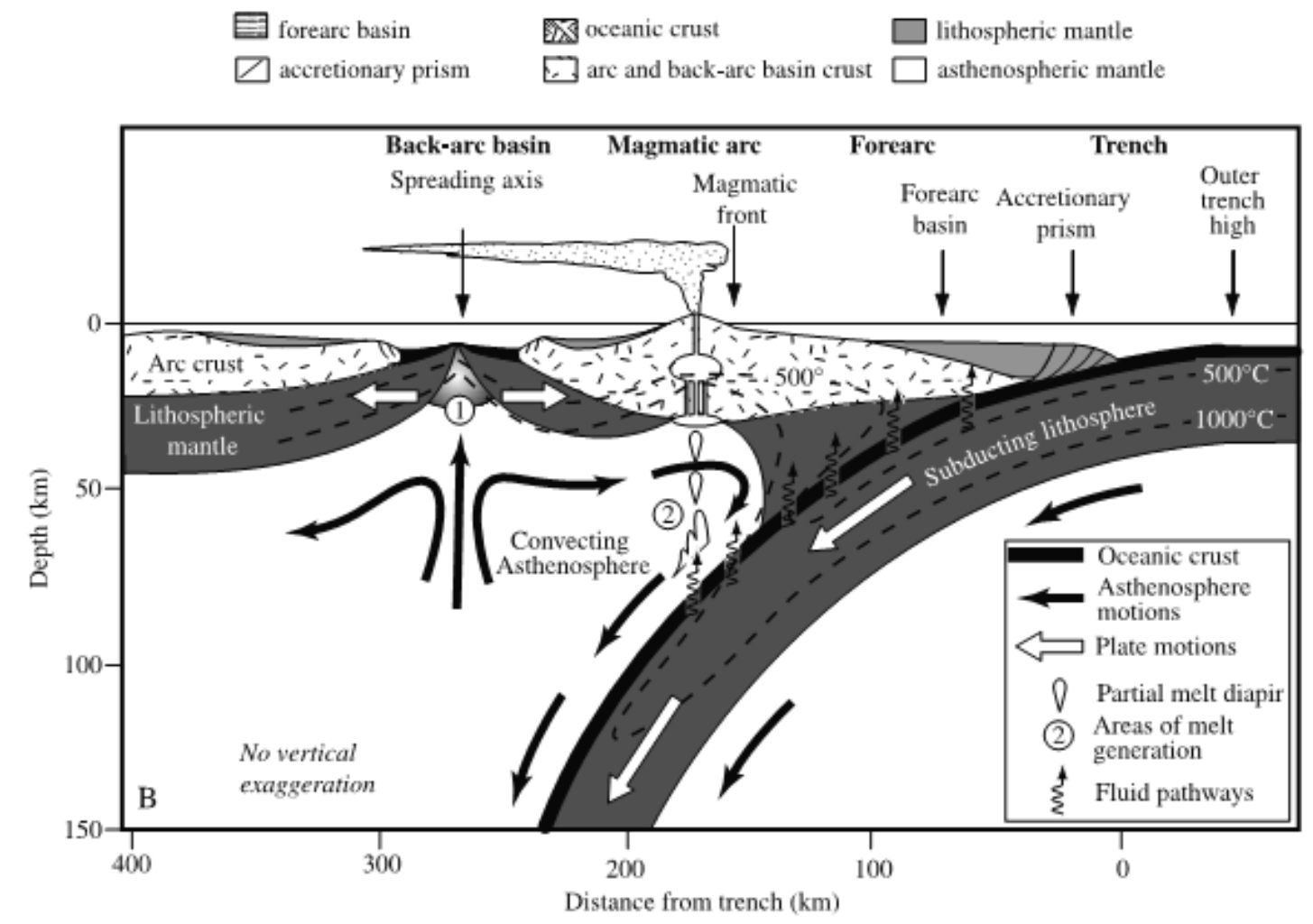

Gambar: 1. Sistem kompleks pada zona subduksi [2]

aktivitas tektonik yang sering terjadi adalah gempa tektonik. Kegempaan (seismisitas) pada zona subduksi terjadi akibat gesekan antar lempeng yang memicu pelepasan energi. Efektivitas gaya gesek yang terjadi pada zona subduksi dipengaruhi oleh banyak faktor. Faktor-faktor tersebut antara lain sifat fisis material, keberadaan fluida, kekasaran seafloor, geometri slab, suhu dan tekanan [3]. Berdasarkan penelitian-penelitian yang telah dilakukan, aktivitas kegempaan memiliki pengaruh dalam memicu aktivitas erupsi gunungapi $[4,5]$.

Sifat atau aktivitas kegempaan yang terjadi pada zona subduksi dapat diketahui melalui Trench-Parallel Gravity Anomali (TPGA). Daerah dengan TPGA positif memiliki kecenderungan potensi seismik magnitudo besar lebih rendah dibandingkan daerah dengan TPGA negatif. Hal ini dikarenakan TPGA negatif berasosiasi dengan gaya gesekan yang kuat, dan sebaliknya [6].

Berbagai penelitian dilakukan guna menyelidiki struktur, aktivitas, maupun dinamika yang terjadi di dalam sistem subduksi Jawa Timur. Hal ini dilakukan guna mengurangi dampak bencana yang dapat ditimbulkan. Kajian-kajian tersebut dilakukan baik menggunakan data aktivitas seismik, data gravitasi, maupun perpaduan antara keduanya[7]. Berbagai metode dikembangkan untuk memberikan pendekatan model dan hasil yang lebih baik dan mendekati kondisi yang sebenarnya.

Salah satu cara untuk memodelkan struktur bawah permukaan berdasarkan data gravitasi adalah menggunakan model blok. Pemodelan ini menggunakan metode inversi Singular Value Decomposition (SVD) dan Occam dalam melakukan optimasi model [8].

Penggunaan model blok dalam memodelkan struktur bawah permukaan zona subduksi Jawa Timur belum pernah dilakukan. Oleh karena itu, pengunaan model blok dalam memodelkan struktur subduksi Jawa Timur menjadi menarik untuk dilakukan.

\section{Metode Penelitian}

Penelitian dilakukan dengan menggunakan data sekunder anomali gravitasi yang diunduh dari laman resmi Bureau Gravimetrique Internationale (BGI). Data yang diunduh terdiri atas data anomali udara 


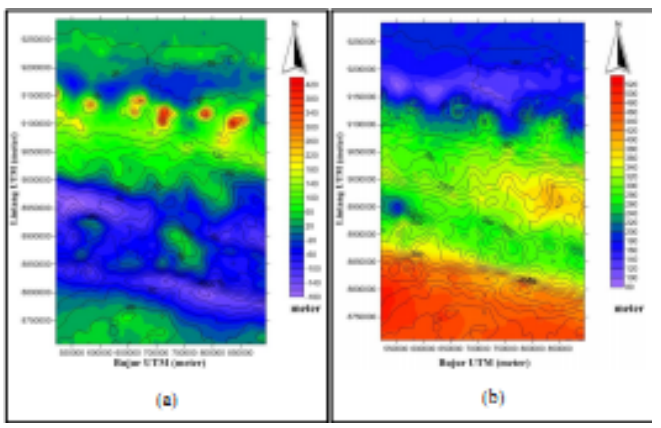

Gambar 2: (a) Anomali udara bebas FAA, (b) Anomali Bouguer lengkap (ABL), dalam koordinat UTM

bebas, anomali Bouguer lengkap, dan topografi. Lokasi daerah penelitian terletak pada posisi $111,20^{\circ} \mathrm{BT}$ $-114,56^{\circ} \mathrm{BT}$ dan $6,46^{\circ} \mathrm{LS}-11,68^{\circ} \mathrm{LS}$ dengan spasi grid antar titik sejauh 2 menit. Selain data gravitasi, penelitian ini menggunakan data hiposenter gempa yang terjadi pada rentang waktu antara tahun 1976-2014 yang diunduh dari katalog International Seismological Center (ISC) dan data aktivitas gunungapi sampai tahun 2011 yang diperoleh dari Pusat Volkanologi dan Mitigasi Bencana Gunungapi (PVMBG).

Pengolahan dilakukan dengan menggunakan bantuan beberapa perangkat lunak yang terdiri atas Grablox 1.6b, Bloxer 1.5a, Microsoft Excel, Matlab, Transkoordinat 1.01, Surfer 11, dan Magpick.

Data anomali gravitasi yang di unduh masih menggunakan koordinat geografis. Guna memudahkan dalam pengolahan selanjutnya, maka koordinat geografis di ubah ke dalam format koordinat UTM. Adapun daerah penelitian terdiri atas dua zona, yakni zona 49S dan $50 \mathrm{~S}$, maka dilakukan tranfsormasi zona UTM dari 50S ke dalam 49S. Peta kontur anomali gravitasi dalam koordinat UTM ditunjukkan pada Gambar 2.

Proses selanjutnya dilakukan pengolahan anomali Bouguer lengkap lebih lanjut. Adapun langkah-langkah pengolahan tersebut adalah sebagai berikut:

1 Melakukan proyeksi ke bidang datar dengan metode Dampney [9].

2 Melakukan pemisahan anomali regional dan residual (lokal) dengan metode kontinuasi ke atas.

Setelah diperoleh anomali gravitasi regional dan lokal, maka selanjutnya dilakukan pembuatan model awal untuk memodelkan struktur subduksi. Oleh karena subduksi merupakan suatu struktur geologi yang bersifat regional, maka pemodelan dilakukan dengan menggunakan anomali regional. Sedangkan

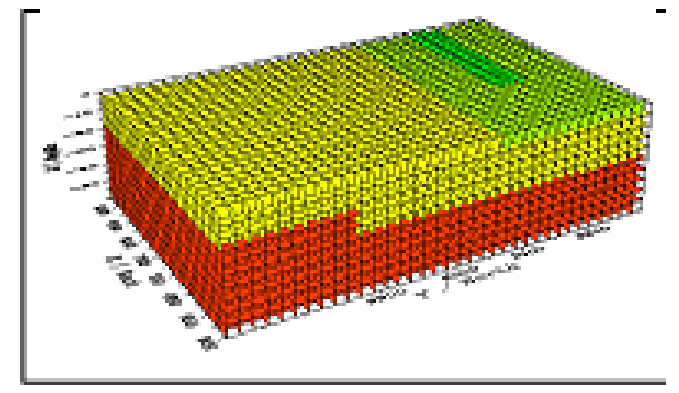

Gambar 3: Model awal untuk memodelkan anomali. regional

anomali lokal digunakan untuk memodelkan struktur dangkal di bawah permukaan daerah Jawa Timur.

Tahapan pemodelan dilakukan dengan membuat model awal (model blok) yang dikontrol oleh kondisi geologi (Gambar 3). Model awal dibuat dengan memasukkan parameter-parameter fisis seperti nilai densitas, dan posisi blok (x, y, z).

Selanjutnya dilakukan proses inversi dengan metode SVD dan Occam untuk membentuk struktur bawah permukaan. Inversi dengan menggunakan metode SVD terdiri atas inversi base, density, dan height. Sedangkan inversi dengan metode Occam terdiri atas occam d dan occam h. Proses pelaksanaan pemodelan anomali gravitasi secara umum dapat dilihat pada Gambar 4.

Pengolahan data hiposenter gempa dimaksudkan untuk mengetahui persebaran aktivitas kegempaan yang terjadi di daerah penelitian. Berdasarkan persebaran nantinya digunakan untuk membantu interpretasi model bawah permukaan yang dibuat. Adapun langkah-langkah yang digunakan sebagai berikut:

1 Mengubah data dari format *.txt ke dalam lembar kerja Ms. Excel

2 Memilih gempa-gempa dengan magnitudo $\mathrm{Mw}$ $\geq 4,00$

3 Membuat script program untuk memploting posisi hiposenter gempa

4 Menampilkan hiposenter gempa dalam bentuk gambar

Alur kerja pembuatan peta distribusi hiposenter gempa yang terjadi di zona subduksi Jawa Timur ditunjukkan pada Gambar 5.

\section{Hasil dan Pembahasan}

\subsection{Peta Anomali Bouguer Lengkap Daerah Penelitian}

Peta anomali gravitasi Bouguer lengkap daerah penelitian dalam koordinat UTM ditunjukkan pada Gambar 2b. Berdasarkan gambar tersebut, anomali 


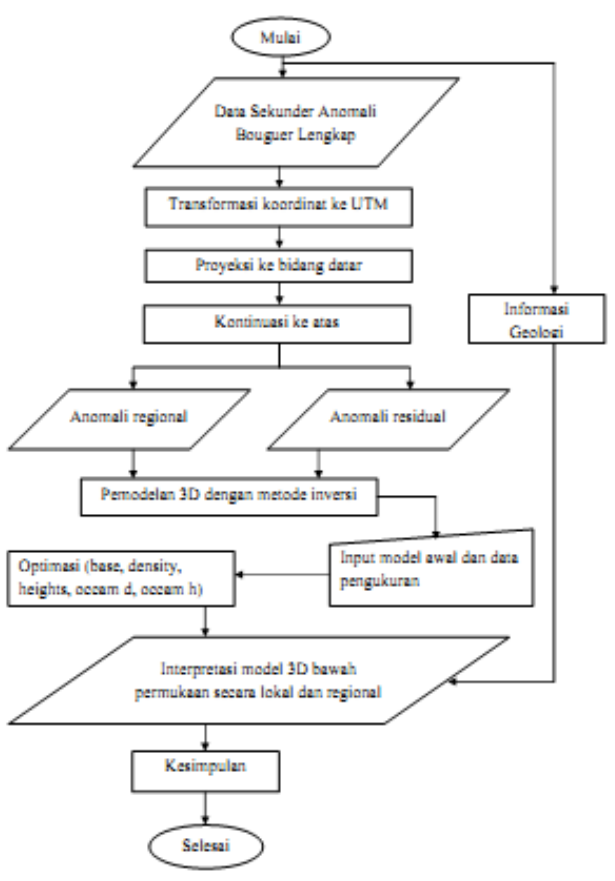

Gambar 4: Diagram alir pemodelan anomali gravitasi

gravitasi positif tertinggi berada pada daerah di selatan palung Jawa, anomali gravitasi positif bernilai sedang berada pada daerah fore-arc basin, sedangkan anomali gravitasi paling rendah berada pada daerah utara, yakni pada bagian pulau Jawa bagian timur.

Nilai anomali Bouguer lengkap berada pada rentang antara 80-520 mGal. Profil anomali gravitasi tersebut dapat dilihat pada Gambar 6. Profil anomali udara bebas menunjukkan pengaruh topografi terhadap nilai anomalinya, sedangkan profil anomali Bouguer lengkap menunjukkan pengaruh tersebut telah dihilangkan saat melakukan koreksi topografi.

\subsection{Turunan Horizontal Pertama Anomali Gravitasi}

Analisis turunan horizontal pertama dilakukan guna mengetahui batas tepi lempeng kerak samudera dan kerak benua. Posisi batas tepi tersebut ditunjukkan oleh nilai terendah dari turunan horizontal pertama anomali gravitasi. Proses pembuatan turunan horizontal pertama dilakukan terhadap hasil sayatan peta anomali regional yang ditunjukkan pada Gambar 7. Berdasarkan analisis yang telah dilakukan diperoleh posisi tersebut berada pada daerah di sepanjang palung Jawa. Posisi tersebut ditabulasikan pada Tabel 1.

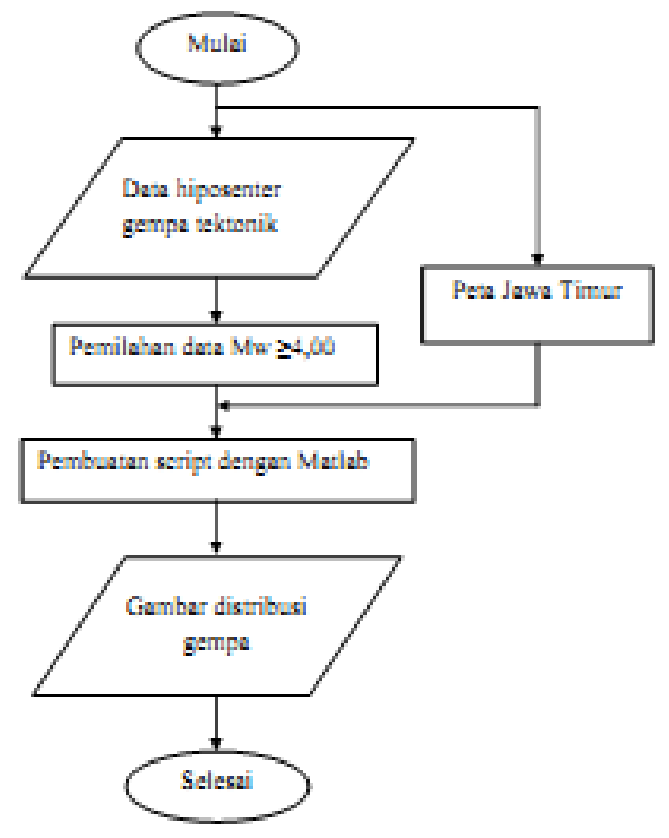

Gambar 5: Diagram alir pembuatan peta gempa tektonik

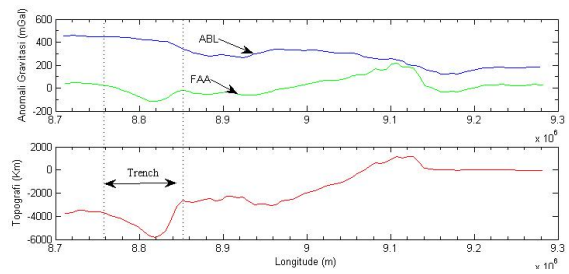

Gambar 6: Profil FAA, ABL, dan topografi pada sayatan bujur $\mathrm{UTM}=700000$

Tabel 1: Posisi batas tepi lempeng samudera sebelum menumbuk

\begin{tabular}{|c|c|}
\hline Sayatan ke- & Lintang UTM (meter) \\
\hline 1 & \pm 8886569 \\
\hline 2 & \pm 8884089 \\
\hline 3 & \pm 8883148 \\
\hline 4 & \pm 8878174 \\
\hline 4 & \pm 8858701 \\
\hline 5 & \pm 8850939 \\
\hline
\end{tabular}

\subsection{Pemodelan Anomali Regional}

Pemodelan anomali gravitasi dilakukan dengan menggunakan program Grablox dan Bloxer. Jumlah blok utama dibuat sebanyak sepuluh lapisan dengan ketebalan setiap lapisan sebesar $6 \mathrm{~km}$.

Berdasarkan pemodelan yang telah dilakukan diperoleh gambaran struktur bawah permukaan zona subduksi Jawa Timur. Salah satu sayatan tiga dimensi 


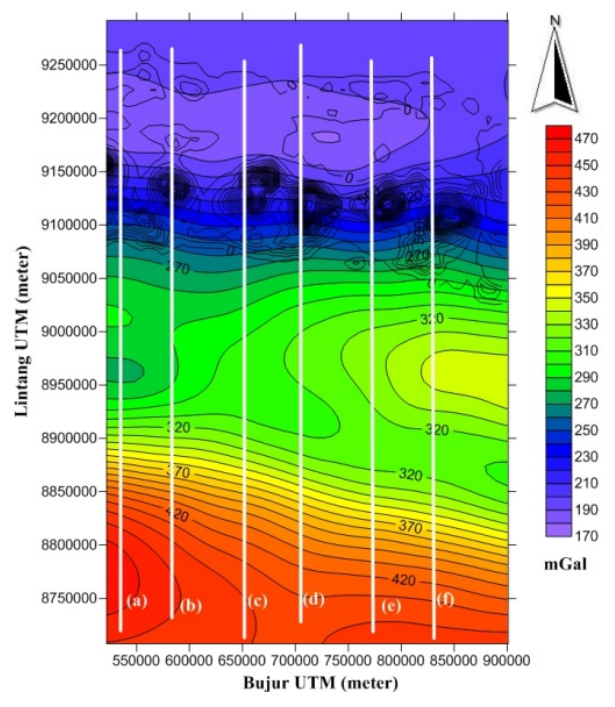

Gambar 7: Posisi sayatan untuk analisis turunan horizontal pertama anomali regional (a) sayatan pertama, (b) sayatan kedua, (c) sayatan ketiga, (d) sayatan keempat, (e) sayatan kelima, dan (f) sayatan keenam

struktur bawah permukaan tersebut ditampilkan pada Gambar 8.

Model tiga dimensi menunjukkan adanya flexural bulge pada daerah subduksi Jawa Timur. Posisi flexural bulge berbeda-beda. Semakin ke timur posisinya semakin ke selatan. Hal ini ditunjukkan pada Gambar 10.

\subsection{Pemodelan Anomali Lokal}

Pemodelan anomali lokal dilakukan dengan membuat model awal sebanyak sepuluh lapisan. Masing-masing lapisan memiliki ketebalan 1,5 km. Model awal yang dibuat disesuaikan kondisi geologi daerah penelitian. Pada daerah di bawah busur gunungapi, model blok dibuat dengan nilai densitas lebih besar dibandingkan daerah di sekitarnya.

Gambaran struktur bawah permukaan di daerah pulau Jawa bagian timur ditunjukkan pada Gambar 10. Berdasarkan hasil pemodelan terlihat keberadaan blok dengan densitas ( $3,18 \mathrm{gr} / \mathrm{cm} 3)$ besar di bawah busur gunungapi. Blok massa dengan densitas tersebut diduga sebagai daerah dapur magma. Kedalaman dapur magma tersebut pada umumnya berada pada kedalaman $6 \mathrm{~km}$.

\subsection{Peta Persebaran Hiposenter Gempa}

Persebaran hiposenter gempa tektonik mengindikasikan posisi lempeng samudera yang

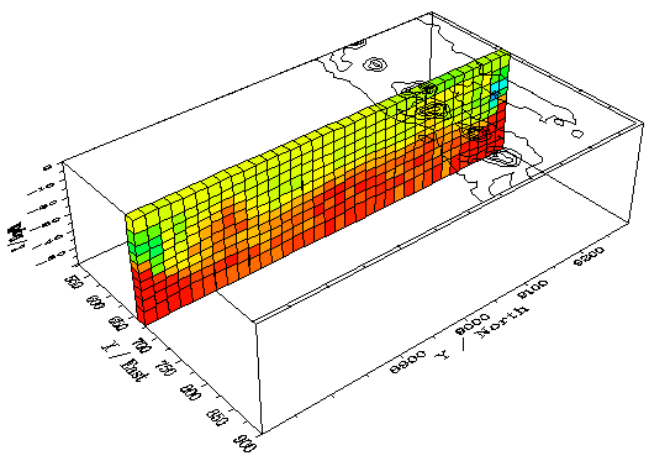

Gambar 8: Sayatan tiga dimensi struktur bawah permukaan subduksi Jawa Timur

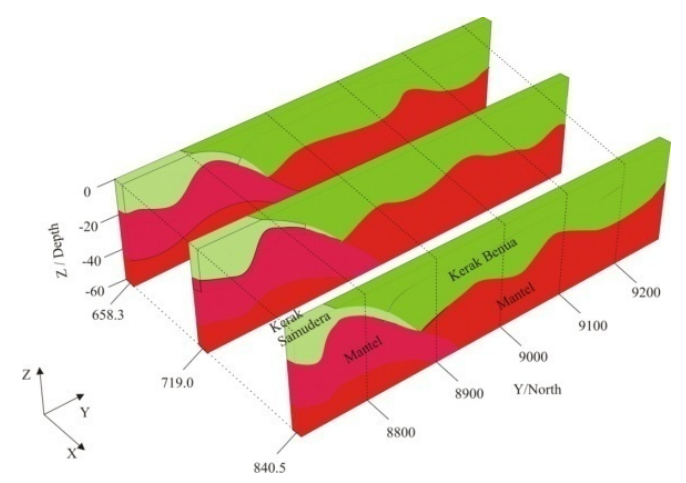

Gambar 9: Kartun tiga dimensi struktur subduksi Jawa Timur

menghunjam lempeng samudera. Kegempaan banyak terjadi pada interface lempeng yang disebabkan gesekan antara kedua lempeng menyebabkan akumulasi energi yang dilepaskan saat mencapai maksimum. Posisi persebaran kegempaan di daerah Jawa Timur ditunjukkan pada Gambar 11.

Gempa-gempa dangkal pada kedalaman 0-20 km (warna merah) banyak tersebar merata di seluruh daerah penelitian. Pada kedalaman 21-40 km (warna coklat) terlihat banyak terdapat di sekitar palung Jawa. Adapun gempa-gempa pada kedalaman 41-100 km (warna hitam, kuning, dan hitam) tersebar pada daerah fore-arc basin. Adapun kegempaan dengan kedalaman 101-200 km banyak terlihat pada daerah di bawah busur gunungapi. Sedangkan gempa-gempa dalam $(>200 \mathrm{~km}$ ) terlihat di daerah pulau Jawa bagian utara (warna hijau).

\section{Kesimpulan}

Beberapa hal yang dapat disimpulkan berdasarkan pembahasan yang dilakukan sebagai berikut: 1. Peta persebaran anomali Bouguer lengkap positif tertinggi 


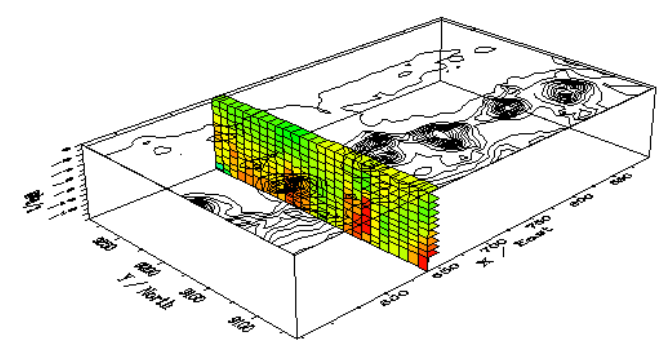

Gambar 10: Sayatan tiga dimensi hasil pemodelan anomali lokal

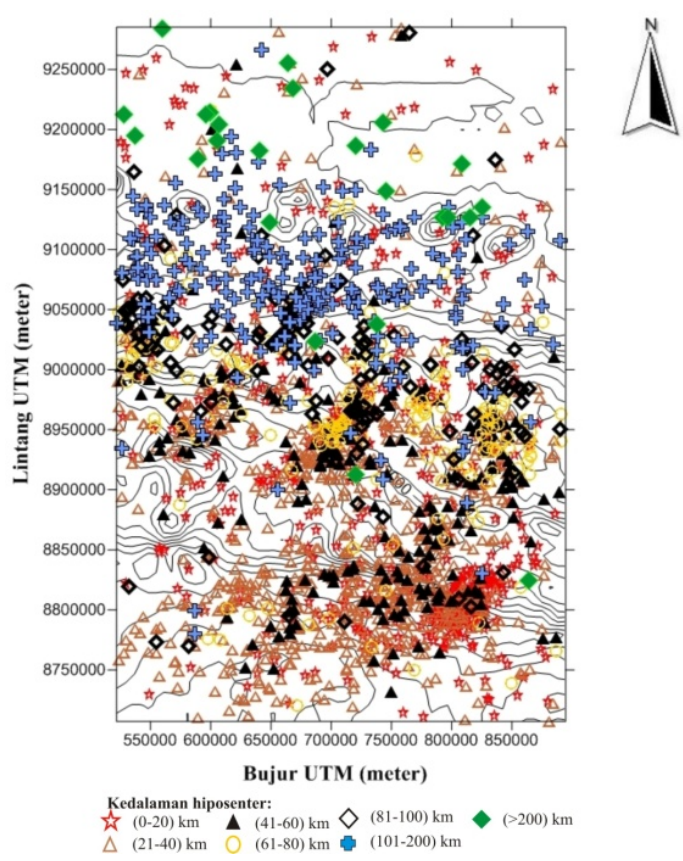

Gambar 11: Peta persebaran hiposenter gempa di daerah Jawa Timur berada pada bagian selatan palung Jawa, sedangkan anomali positif terendah berada pada zona cekungan di tengah Jawa Timur 2. Jarak batas tepi lempeng kerak samudera terhadap kerak benua berada di sepanjang palung Jawa itu sendiri 3. Berdasarkan model tiga dimensi (3D) diperoleh pola penunjaman lempeng Indo-Australia di bawah lempeng Eurasia, yakni ditemukan adanya flexural bulge pada zona subduksi Jawa Timur. Ketebalan lapisan batuan sedimen pada zona back-arc basin diperkirakan sebesar 4,50 km. Adapun pada busur gunungapi ditemukan daerah dapur magma yang pada umumnya mulai terlihat pada kedalaman $6 \mathrm{~km}$.

Pustaka

1. http://www.vsi.esdm.go.id/index.php/gunungapi Accessed 2014-10-01

2. Stern, R.J.: Subduction zones. Reviews of Geophysics 40(4), 1012 (2002). doi:10.1029/2001RG000108

3. Campione, M., Gian, C.C.: Subduction-zone eartquake complexity related to frictional anisotropy in antigorite. Nature Geoscience (6), 847-851 (2013)

4. Eggert, S., Thomas, R.W.: Volcanic activity before and after large tectonic earthquakes: Observation and statistical significance. Tectonophysics (471), 14-26 (2009)

5. Watt, S.F.L., David, M.P., Tamsin, A.M.: The influence of great earthquakes on volcanic eruption rate along the chilean subduction zone. Earth and Planetray Science Letter (277), 399-407 (2009)

6. Song, T.R., Simons, M.: Large trench-parallel gravity variations predict seismogenic behavior in subduction zones. Science (301), 630-633 (2003)

7. Shulgin, A., Kopp, H., Mueller, C., Planert, L., Lueschen, E., Fluech, E.R., Djajadiharja, Y.: Structural architecture of oceanic plateu subduction offshore Eastern Java and potential implication for geohazards. Geophysical Journal International (184), 12-28 (2011)

8. Pirttijarvi, M.: Grablox, Gravity Interpretation and Modeling Software Based on a 3-D Block Model. University of Oulu, (2008). University of Oulu

9. Dampney, C.N.G.: The equivalent source technique. Geophysics 34(1), 35-39 